\title{
REGIONAL TOURISM CLUSTERS SUSTAINABILITY MODELING TAKING INTO ACCOUNT SOCIOCULTURAL FACTORS
}

\author{
Sabalenka Ina ${ }^{1}$, Krupenka Yuliya ${ }^{2}$, Ganski Uladzimir ${ }^{3}$, Zhou Weidi $^{4}$ \\ ${ }^{1}$ Asist. prof. Belarusian National Technical University. Niezaliežnasci 65, 220013 Minsk, Belarus. E-mail address: \\ sabalenka_ia@bntu.by \\ ${ }^{2}$ Assoc. prof. Dr. Yanka Kupala State University of Grodno. Elizy Ažeški 22, 230023 Grodno, Belarus. E-mail address: \\ ulia_kul@grsu.by
} ${ }^{3}$ Assoc. prof. Dr. habil. Institute of Entrepreneurial Activity. Sierafimoviča 11, 220033 Minsk, Belarus. E-mail address:
ganski.uladzimir@gmail.com

${ }^{4}$ Prof. Dr. habil. Central China Normal University. Luoyu Avenue 152, 430079 Wuhan, China. E-mail address: zhouweidiccnu@gmail.com

Received 0808 2021; accepted 09082021

\begin{abstract}
In studies devoted to the problem of tourism development in the host regions (destinations), the economic component is always taken into account, sometimes the environmental component, and almost never the sociocultural component is taken into account. However, today the problem of organizing investment in the tourism business, taking into account the environmental and cultural impact, is becoming more and more urgent. It causes a great practical need for conducting research on the investment process in the tourism business and theoretical justification of the choice of areas of investment activity activation in compliance with the criteria of economic efficiency, sociocultural sustainability and environmental safety. In the course of writing the article, the authors set a goal to demonstrate the possibilities of taking into account cultural factors in the process of modeling the socioeconomic sustainability of regional tourist clusters based on qualitative methods. Qualitative methods were chosen as the methodological basis for modeling, which allow us to systematize and formalize the main patterns of development and identify the vector of the most effective use of available resources. The formation of models describing the economic, environmental and sociocultural sustainability of the destination, which allow identifying key factors of sustainable development can help ensure a long-term positive effect from the development of tourism in the region. The results of this study have theoretical and practical significance. They can be used as a basis for further scientific research and can also be used in the practical activities of tourism business entities, as well as state and local authorities and other stakeholders in the process of analytical justification of investment activities implemented on the basis of the principles of sustainable development.
\end{abstract}

Keywords: clusters, modeling, sustainable development, tourism, cultural heritage, destination.

JEL Codes: C19, C38, Z32.

\section{Introduction}

The concept of sustainable development occupies a leading place today among the world trends in the development of both the economy in general and tourism in particular. The experience of many countries and regions of the world shows that the development of tourism, the main and only goal of which is only to make a quick profit, destroys the basis necessary for the successful and harmonious functioning of the tourism industry. Moreover, negative phenomena from such activities can be observed both in the natural and cultural spheres. The following negative aspects of the impact of the growth of uncontrolled tourist consumption on the economic, environmental and socio-cultural spheres of life of the host territory (destination) can be distinguished: direct and indirect harm to objects of historical, cultural and natural heritage; cultural degradation of the territory; aggravation of complex socio-economic problems, pollution or even destruction of the natural environment,

Copyright (C) 2021 Author(s), published by Vytautas Magnus University. This is an open access article distributed under the terms of the Creative Commons Attribution Non-Commercial 4.0 (CC BY-NC 4.0) license, which permits unrestricted use, distribution, and reproduction in any medium provided the original author and source are credited. The material cannot be used for commercial purposes. 
etc. Although the popularity of most tourist centers (destinations) is often based on the existing heritage sites and the uniqueness of the local culture.

There are several types of sustainability of regional tourism clusters. Economic sustainability ensures the economic efficiency of the territory's development and a situation in which the chosen method of managing existing resources (both natural and cultural heritage objects) makes it possible for future generations to use them, among other things. Environmental sustainability ensures the compatibility of development with the maintenance of basic ecological processes, biological diversity and the wealth of natural resources. Sociocultural stability provides a situation in which development is compatible with the preservation of the way of life, the basic elements of material and spiritual culture embodied in the cultural and historical heritage, as well as in the local ethnocultural identity. To achieve true sustainability of a regional tourism cluster, it is necessary to combine and complement all three of these types of sustainability.

The goal of article is to demonstrate the possibility of taking into account socio-cultural factors in modeling the socio-economic stability of regional tourist clusters based on qualitative methods.

To date, a significant number of publications on clusters have been accumulated in the world economic science. These are primarily publications by Michael Porter (1990;1998a; 1998b), as well as publications by other scientists that demonstrate other, including new ideas, for example, S. A. Rosenfeld (1997), T. J. A. Roelandt \& P. den Hertog (1999), A. Malmberg \& D. Power (2006), G. M. Spencer et al. (2010). Their publications often consider theories that reflect the emergence, evolution, life cycle and mechanisms of a particular business area. Typical in this regard are the publications of I. Paniccia (2006), G.-J. Hospers et al. (2008). Conceptually, these publications, in most cases, cannot be considered specialized in relation to the tourism business, but sometimes they show examples of territorial or sectoral case studies. At the theoretical level, tourism is usually not taken as the main example for describing the theory of clusters, although they may be included in the list of examples of clustering (J. Swords, 2013). In some works, tourism is used as an example to emphasize general details, as, for example, M. Porter does (2000). In addition to such scientific sources, a significant number of publications of a general theoretical nature on tourism as such have been accumulated in the world economic science. These are, for example, the works of B. Kirshenblatt-Gimblett (1998), R. Sharpley (2009), J. Aramberri (2010), M. Dujmović \& A. Vitasović (2015) and others, which very rarely contain theoretical developments or conceptual ideas about the clustering of the tourism business.

If we talk about publications of an empirical nature and the characteristics of tourist clusters, then there are many case studies in the modern scientific literature. Tourism clustering still occupies an important place in the scientific interests of M. Porter. This follows from the fact that his institute at the Harvard Business School has published many case studies on tourism clusters in recent years. Other authors analyze tourist clusters from the point of view of the importance of integration ties (M. Partalidou \& S. Koutsou, 2012) or there is a mutual dependence between the tourist cluster and the corresponding policy (J. Steenbruggen, 2016). In the field of empirical research, there are data on the prevalence of external factors caused by clustering in tourist regions (M. Segarra-Oña et al., 2012), confirming that the cluster is a very important factor of economic development today.

The scientific works of many researchers are devoted to the consideration of the problem of sustainable development in the field of tourism. For example, indicators of sustainable tourism are studied by M. C. Ottenbacher et al. (2015). Individual aspects of the sustainable development of a tourist destination are considered by J. B. Greenwood (2006). The author's methodology for modeling the sustainable development of regional clusters in agrotourism offers by Kazlovski et al. (2020). The study of self-efficacy and sustainable development of tourism was conducted by S. F.Fong et al. (2017), and research and the reality of sustainable tourism are considered by $\mathrm{R}$. Buckley (2012). An evolutionary analysis of sustainable tourism, analyzed by $\mathrm{P}$. He et al. (2018). The issues of interaction between the 


\section{Sciendo}

Management Theory and Studies for Rural Business and Infrastructure Development

eISSN 2345-0355. 2021. Vol. 43. No. 4: 457-467

Article DOI: https://doi.org/10.15544/mts.2021.41

territory and the sustainable development of tourism are being investigated by J. Romao et al. (2017). The regional aspect of the model of sustainable development of the tourism industry was studied by E. B. Aimagambetov et al. (2017) and others. At the same time, researchers pay great attention to the theoretical development of the concept of tourism sustainability and its provision. Modeling of the prospects for sustainable development of territories was studied by M. Tymošenko \& K. Golovach (2018), and the dynamic model of sustainable tourism was studied by T. J. Tyrell \& R. J. Johnston (2005). M. Benner (2017) studied tourism in the policy of regional development, taking into account institutional aspects, in the context of the transition from clusters to reasonable specialization. The analysis of spatiotemporal models of tourism in Europe with high resolution using traditional and large data sources is investigated by F. Batista e Silva et al. (2018) and others. However, the methods proposed by the authors only partially reflect the specifics of the stability of tourist clusters, which is based on both economic and environmental, and socio-cultural stability, and therefore the results obtained by them are not directly related to modeling the sustainable development of tourist clusters, considering cultural factors.

\section{Methodology}

The main problem of modeling tourist clusters in many destinations is the lack of sufficient statistical data. In addition, the tourism industry is a complex object consisting of various subsystems, the functioning of which depends on many external factors. These factors are sometimes almost impossible to measure quantitatively, but it is possible to measure qualitatively, that is, to assess the impact of qualitative factors on quantitative indicators and how they are interrelated.

Qualitative modeling is a formalized algorithm of logical thinking that allows you to create a simulation model of a complex system. The first step of qualitative modeling is to identify all the variables of a model: $X_{1}, X_{2}, \ldots$, $X n$. The generated set of variables contains both exogenous and endogenous variables. At the next step, using the methods of formal logic, the method of expert assessments or the results obtained by quantitative methods, it is necessary to determine the paired interdependencies of variables. Figure 1 shows examples of six possible dependencies between two variables.
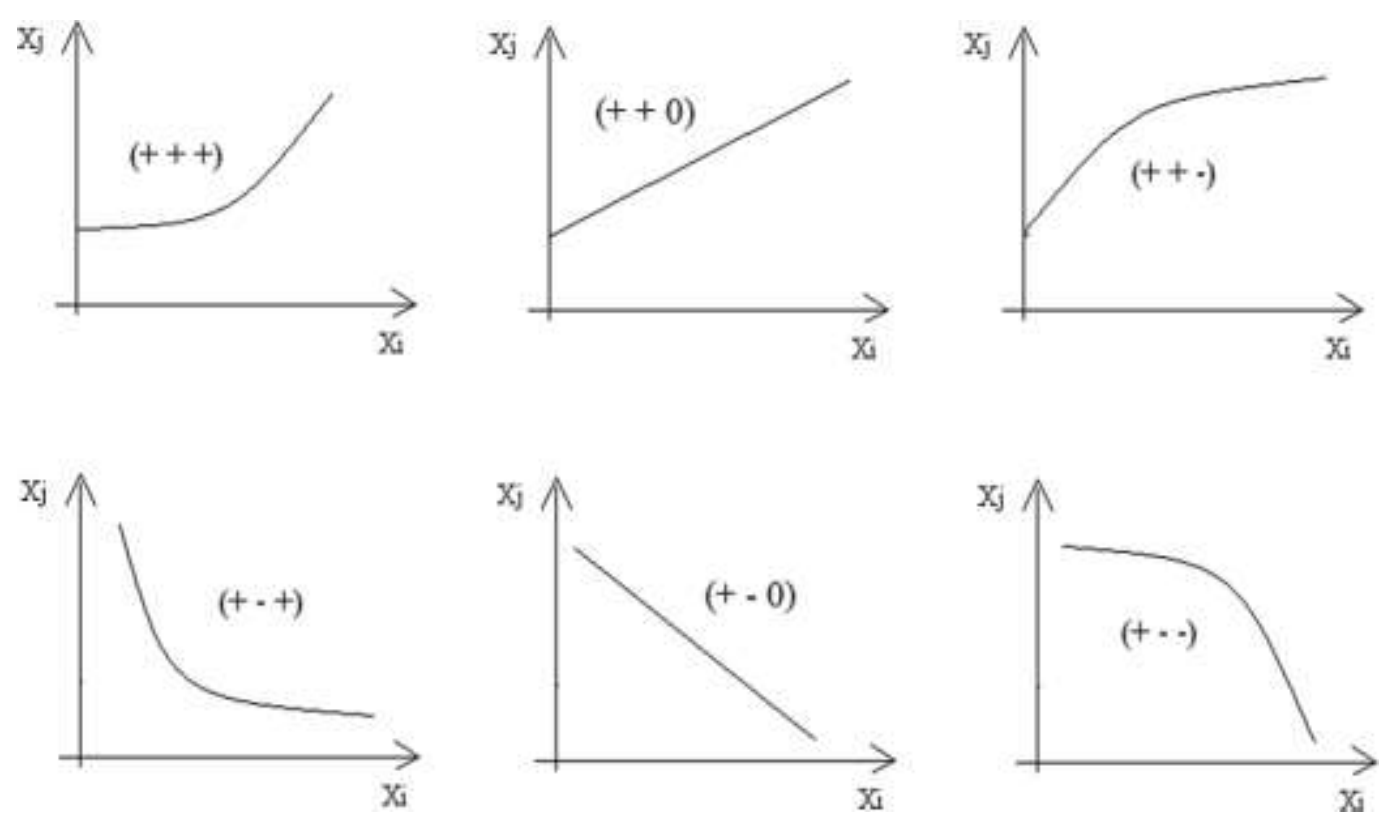

Figure 1. Variability of qualitative dependencies in the model 
With the help of these graphs, you can formalize information that cannot be taken into account using ordinary equations. The relationship between each two variables is described using a triplet:

$$
\left(X_{j}, D X_{j} / D X_{j}, D D X_{j} / D D X_{j}\right)
$$

It is obvious that variables are not always connected by an unambiguous dependence, which means that it is not always possible to describe paired relationships between all variables. However, qualitative modeling does not require the definition of all paired dependencies: it is enough to determine a reasonable number of logical relationships. A qualitative solution is considered definite if all the qualitative variables are described by the corresponding qualitative triplets:

$$
\begin{gathered}
\left(X_{1}, D X_{1}, D D X_{1}\right) \\
\left(X_{2}, D X_{2}, D D X_{2}\right), \ldots,\left(X_{n}, D X_{n}, D D X_{n}\right),
\end{gathered}
$$

where $X_{j}$ this is the $i^{\text {th }}$ variable; $D X_{j}$ and $D D X_{j}$ is respectively, the first and second qualitative derivatives of the independent variable $t$ (usually $t$ is a time parameter).

The qualitative model has $m$ qualitative solutions (scenarios). A set of $m$ qualitative $n$ dimensional scenarios can be described using the following set of triplets:

$$
\left[\begin{array}{c}
\left(X_{1}, D X_{1}, D D X_{1}\right) \\
\left(X_{2}, D X_{2}, D D X_{2}\right), \ldots \\
\left(X_{n}, D X_{n}, D D X_{n}\right)
\end{array}\right]_{j}, j=1,2, \ldots, m
$$

Using a simple algorithm that obeys mathematical principles, it is possible to determine all possible transitions for onedimensional triplets. For example, a triplet $(--+)$ can change to a triplet (--0), or $(-0+)$, or $(-00)$. Accordingly, for $n$-dimensional transitions, it is necessary to observe the implementation of the transition rules for $n$ one-dimensional transitions.

To illustrate multidimensional qualitative variables, it is convenient to use a directed graph in which the vertices represent a set of scenarios, and the directed arrows represent possible transitions between scenarios.
The described qualitative model is a flexible modeling tool and allows you to analyze the development of systems that have exceptional properties or are strongly influenced by qualitative factors.

\section{Results}

As an example, the article will consider two models: a two-factor EE-model (Economy $\&$ Ecology), in which the target variables will be economic and environmental indicators, and a three-factor EEC-model (Economy, Ecology \& Culture), in which a sociocultural factor will be added to economic and environmental indicators.

We will introduce the following variables into the qualitative EE-model of the development of the tourist complex.

Private investment in the tourism industry (InvPr). Investments are a determining factor in the development of any industry, region or cluster. The main problem of the tourism industry is high seasonality: a large flow of tourists falls on the summer period. Hence, there is a need to develop, for example, all-season or winter types of tourism. The prospects and return on investment, for example, in a ski resort are well understood at the international level, so when creating a favorable investment climate for international investment, we can expect the development of this type of tourism.

Public investments in the tourism industry (InvPu). Public investments are necessary for the development of the region's infrastructure, the low level of which today is most often one of the main constraining factors for the development of tourism.

Public investment in the environment (InvEn). These investments are necessary to preserve the ecological balance, which should be controlled at the highest level.

The level of development of winter tourism (TourW). The development of winter tourism will solve the problem of seasonality. The presence of a well-developed winter tourism infrastructure will significantly increase the image of the destination, since many types of winter tourism, in particular ski tourism, are very popular all over the world.

Infrastructure (Inf). This is a necessary factor in the development of the tourism industry. 


\section{sciendo}

Without a developed infrastructure, it is impossible to attract a sufficient amount of private investment, which means that it is impossible to turn a particular region into a successful destination. It is obvious that the development of infrastructure will inevitably lead to a deterioration of the environment. Therefore, it is necessary to take measures to compensate for this negative impact.

The image of the region (Image). The image of the region is important for both investors and tourists. Therefore, this factor also affects the attraction of private investment and the profitability of the entire tourist industry as a whole.

Ecology (Eco). This is a factor that must be taken into account in order to preserve the uniqueness of the natural heritage and ensure the sustainable development of the region.
Profitability of the tourism business (Profit). This indicator characterizes the efficiency of the functioning of the tourism business, affects the success of attracting private investment.

The first part of Table 1 shows all the relationships of variables in the EE-model, based on the judgments expressed above, and written in the form of triplets.

Let's add the ninth indicator to the qualitative model - sociocultural satisfaction (CultS). It manifests itself in improving the sociocultural comfort of local communities, in supporting and expanding the historical and cultural heritage by contributing to its comprehension and preservation. Sociocultural comfort is largely determined by the level of public investment, and also increases if tourism brings income to the local population. Thus, the second part of Table 1 shows the relationships of variables in the EEC-model.

Table 1. Qualitative Dependencies

\begin{tabular}{|c|c|c|c|c|c|c|c|c|c|c|c|c|c|c|c|c|c|c|}
\hline \multicolumn{9}{|c|}{ EE-model } & \multicolumn{10}{|c|}{ EEC-model } \\
\hline & $\stackrel{\vec{\lambda}}{\vec{\Xi}}$ & $\stackrel{\vec{J}}{\vec{\Xi}}$ & $\stackrel{\text { ज्ञ̃ }}{\gtrsim}$ & $\begin{array}{l}3 \\
\stackrel{3}{0} \\
\stackrel{0}{\ominus}\end{array}$ & $\leftrightarrows$ & 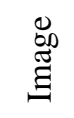 & 嵳 & $\begin{array}{l}\text { 苛 } \\
\text { D. }\end{array}$ & & 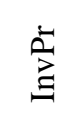 & $\stackrel{\vec{J}}{\stackrel{\Xi}{\Xi}}$ & $\stackrel{\text { ज్ }}{\gtrsim}$ & 訔 & $\Xi$ & $\begin{array}{l}0 \\
\mathbb{8} \\
\Xi \\
\Xi\end{array}$ & $\begin{array}{c}8 \\
\text { II }\end{array}$ & $\begin{array}{l}\vec{E} \\
\dot{0} \\
\dot{0}\end{array}$ & $\stackrel{\mathscr{y}}{\mathrm{Z}}$ \\
\hline InvPr & & & & ++ & & & & & InvPr & & & & ++ & & & & & \\
\hline InvPu & & & & & ++ & & & & InvPu & & & & & ++ & & & & ++- \\
\hline InvEn & & & & & & & ++0 & & InvEn & & & & & & & ++0 & & \\
\hline TourWin & & & & & & ++- & & & TourWin & & & & & & ++ & & & \\
\hline Inf & ++ & & & & & & ++-+ & & Inf & ++ & & & & & & +-+ & & \\
\hline Image & ++0 & & & & & & & ++0 & Image & ++0 & & & & & & & ++0 & \\
\hline Eco & & & & & & & & & Eco & & & & & & & & & \\
\hline Profit & ++0 & & & & & & & & Profit & ++0 & & & & & & & & ++ \\
\hline & & & & & & & & & CultS & & & & & & & & & \\
\hline
\end{tabular}

In order to determine all possible qualitative scenarios of the presented models, it is necessary to identify the signs of derivatives of dependent variables based on the independent variables and relationships shown in Table 1. For known values of

$\operatorname{sign}(D Y / D X), \operatorname{sign}(D D Y / D D X)$, $\operatorname{sign}(D X / D t), \operatorname{sign}(D D X / D D t)$ it is necessary to determine the value of

$$
\operatorname{sign}(D Y / D t), \operatorname{sign}(D D Y / D D t) \text {. }
$$

Using the $\mathrm{R}$ programming language, a program was written to search for all possible qualitative scenarios of the models under consideration. As a result, it was found that the EE-model (system "Economy \& Ecology") can be in 23 conditions (Table 2), and the EECmodel (system "Economy, Ecology \& Culture") can be in 35 conditions. 
Table 2. Qualitative scenarios

\begin{tabular}{|c|c|c|c|c|c|c|c|c|c|c|c|c|c|c|c|c|c|}
\hline & \multicolumn{8}{|c|}{ EE-model } & \multicolumn{9}{|c|}{ EEC-model } \\
\hline & $\begin{array}{l}8 \\
\text { I }\end{array}$ & $\begin{array}{l}\mathscr{E} 0 \\
\stackrel{\Xi}{\Xi} \\
\Xi\end{array}$ & $\stackrel{\Psi}{\Xi}$ & 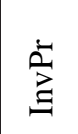 & $\stackrel{\text { II }}{\stackrel{\text { I }}{\Xi}}$ & $\stackrel{\vec{D}}{\vec{\Xi}}$ & $\begin{array}{l}\text { : } \\
\text { D. } \\
\text { D. }\end{array}$ & $\underset{3}{\stackrel{\vec{E}}{\Xi}}$ & $\begin{array}{c}8 \\
\text { II }\end{array}$ & 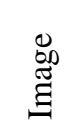 & $\overleftrightarrow{\Xi}$ & $\stackrel{\vec{D}}{\vec{\Xi}}$ & $\stackrel{\tilde{I}}{\gtrsim}$ & $\stackrel{\vec{\Xi}}{\vec{\Xi}}$ & $\begin{array}{l}\stackrel{\#}{0} \\
0 \\
0\end{array}$ & 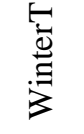 & $\stackrel{\mathscr{I}}{\Xi}$ \\
\hline 1 & +++ & +- & +- & +- & +++ & +- & +- & +- & +++ & +-- & +-- & +-- & +++ & +-- & +-- & +-- & +-- \\
\hline 2 & +++ & +- & +- & +- & +++ & +-0 & +- & +- & +++ & +-- & +- & +-- & +++ & +-0 & +-- & +-- & +-- \\
\hline 3 & ++- & +- & +-+ & +- & ++- & +-+ & +- & +- & ++- & +-- & +-+ & +-- & ++- & +-+ & +-- & +-- & +-- \\
\hline 4 & ++- & +- & +-+ & +- & ++0 & +-+ & +- & +- & ++0 & +-- & +-+ & +-- & ++0 & +-+ & +-- & +-- & +-- \\
\hline 5 & +++ & +- & +- & +- & +++ & +-+ & +- & +- & +++ & +-- & +-- & +-- & +++ & +-+ & +-- & +-- & +-- \\
\hline \begin{tabular}{|l|l}
6 & \\
\end{tabular} & ++0 & +- & +-0 & +- & +++ & +-+ & +- & +- & +++ & +-- & +-0 & +-- & +++ & +-+ & +-- & +-- & +-- \\
\hline 7 & ++- & +- & +-+ & +- & +++ & +-+ & +- & +- & +++ & +-- & +-+ & +-- & +++ & +-+ & +-- & +-- & +-- \\
\hline 8 & $+0+$ & $+0-$ & $+0-$ & $+0-$ & $+0+$ & $+0-$ & $+0-$ & $+0-$ & $+0+$ & $+0-$ & $+0-$ & +0 & $+0+$ & $+0-$ & $+0-$ & $+0-$ & +0 \\
\hline 9 & +-+ & ++- & ++- & ++- & +-+ & ++- & ++- & ++- & +-+ & ++- & ++- & ++- & +-+ & ++- & ++- & ++- & ++- \\
\hline 10 & +-+ & ++- & ++- & ++- & +-+ & ++0 & ++- & ++- & +-+ & ++- & ++- & ++- & +-+ & ++0 & ++- & ++- & ++- \\
\hline \begin{tabular}{|l|}
11 \\
\end{tabular} & +- & ++- & +++ & ++- & +- & +++ & ++- & ++- & +-- & ++- & +++ & ++- & +-- & +++ & ++- & ++- & ++- \\
\hline \begin{tabular}{|l|l|}
12 \\
\end{tabular} & +- & ++- & +++ & ++- & +-0 & +++ & ++- & ++- & +-0 & ++- & +++ & ++- & +-0 & +++ & ++- & ++- & ++- \\
\hline \begin{tabular}{|l|}
13 \\
\end{tabular} & +-+ & ++- & ++- & ++- & +-+ & +++ & ++- & ++- & +-+ & ++- & ++- & ++- & +-+ & +++ & ++- & ++- & ++- \\
\hline 14 & +-0 & ++- & ++0 & ++- & +-+ & +++ & ++- & ++- & +-+ & ++- & ++0 & ++- & +-+ & +++ & ++- & ++- & ++- \\
\hline \begin{tabular}{|l|}
15 \\
\end{tabular} & +- & ++- & +++ & ++- & +-+ & +++ & ++- & ++- & +-+ & ++- & +++ & ++- & +-+ & +++ & ++- & ++- & ++- \\
\hline 16 & +00 & +00 & +00 & +00 & +00 & +00 & +00 & +00 & +00 & +00 & +00 & +00 & +00 & +00 & +00 & +00 & +00 \\
\hline \begin{tabular}{|l|}
17 \\
\end{tabular} & ++- & +-+ & +-+ & +-+ & ++- & +-+ & +-+ & +-+ & ++- & +-+ & +-+ & +-+ & ++- & +-+ & +-+ & +-+ & +-- \\
\hline \begin{tabular}{|l|}
18 \\
\end{tabular} & ++- & +-+ & +-+ & +-+ & ++0 & +-+ & +-+ & +-+ & ++0 & +-+ & +-+ & +-+ & ++0 & +-+ & +-+ & +-+ & +-- \\
\hline 19 & ++- & +-+ & +-+ & +-+ & +++ & +-+ & +-+ & +-+ & +++ & +-+ & +-+ & +-+ & +++ & +-+ & +-+ & +-+ & +-- \\
\hline 20 & $+0-$ & $+0+$ & $+0+$ & $+0+$ & +0 & $+0+$ & $+0+$ & $+0+$ & ++- & +-+ & +-+ & +-+ & ++- & +-+ & +-+ & +-+ & +-0 \\
\hline 21 & +- & +++ & +++ & +++ & +- & +++ & +++ & +++ & ++0 & +-+ & +-+ & +-+ & ++0 & +-+ & +-+ & +-+ & +-0 \\
\hline 22 & +- & +++ & +++ & +++ & +-0 & +++ & +++ & +++ & +++ & +-+ & +-+ & +-+ & +++ & +-+ & +-+ & +-+ & +-0 \\
\hline 23 & +- & +++ & +++ & +++ & +-+ & +++ & +++ & +++ & ++- & +-+ & +-+ & +-+ & ++- & +-+ & +-+ & +-+ & +-+ \\
\hline 24 & & & & & & & & & ++0 & +-+ & +-+ & +-+ & ++0 & +-+ & +-+ & +-+ & +-+ \\
\hline 25 & & & & & & & & & +++ & +-+ & +-+ & +-+ & +++ & +-+ & +-+ & +-+ & +-+ \\
\hline 26 & & & & & & & & & $+0-$ & $+0+$ & $+0+$ & $+0+$ & $+0-$ & $+0+$ & $+0+$ & $+0+$ & $+0+$ \\
\hline 27 & & & & & & & & & +-- & +++ & +++ & +++ & +-- & +++ & +++ & +++ & ++- \\
\hline \begin{tabular}{|l|}
28 \\
\end{tabular} & & & & & & & & & +-0 & +++ & +++ & +++ & +-0 & +++ & +++ & +++ & ++- \\
\hline 29 & & & & & & & & & +-+ & +++ & +++ & +++ & +-+ & +++ & +++ & +++ & ++- \\
\hline \begin{tabular}{|l|}
30 \\
\end{tabular} & & & & & & & & & +-- & +++ & +++ & +++ & +-- & +++ & +++ & +++ & ++0 \\
\hline 31 & & & & & & & & & +-0 & +++ & +++ & +++ & +-0 & +++ & +++ & +++ & ++0 \\
\hline \begin{tabular}{|l|}
32 \\
\end{tabular} & & & & & & & & & +-+ & +++ & +++ & +++ & +-+ & +++ & +++ & +++ & ++0 \\
\hline \begin{tabular}{|l|}
33 \\
\end{tabular} & & & & & & & & & +-- & +++ & +++ & +++ & +-- & +++ & +++ & +++ & +++ \\
\hline 34 & & & & & & & & & +-0 & +++ & +++ & +++ & +-0 & +++ & +++ & +++ & +++ \\
\hline \begin{tabular}{|l|}
35 \\
\end{tabular} & & & & & & & & & +-+ & +++ & +++ & +++ & +-+ & +++ & +++ & +++ & +++ \\
\hline
\end{tabular}

Based on possible one-dimensional transitions, the syntax for constructing a graph of possible transitions between system states was written using the programming language $\mathrm{R}$. The models can be represented as graphs, the vertices of which are the dynamic states of the systems from Table 2 . The arrows indicate the possibility of switching between states (Figures 2 and 3). 


\section{Sciendo}

Management Theory and Studies for Rural Business and Infrastructure Development eISSN 2345-0355. 2021. Vol. 43. No. 4: 457-467

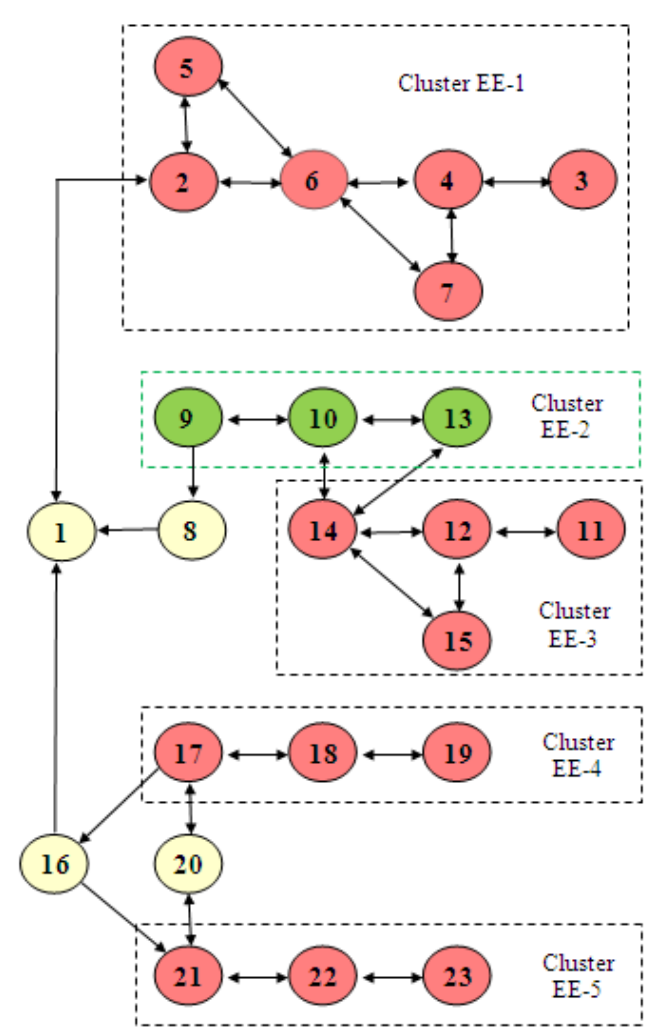

Figure 2. Graph of possible system states in the EE-model

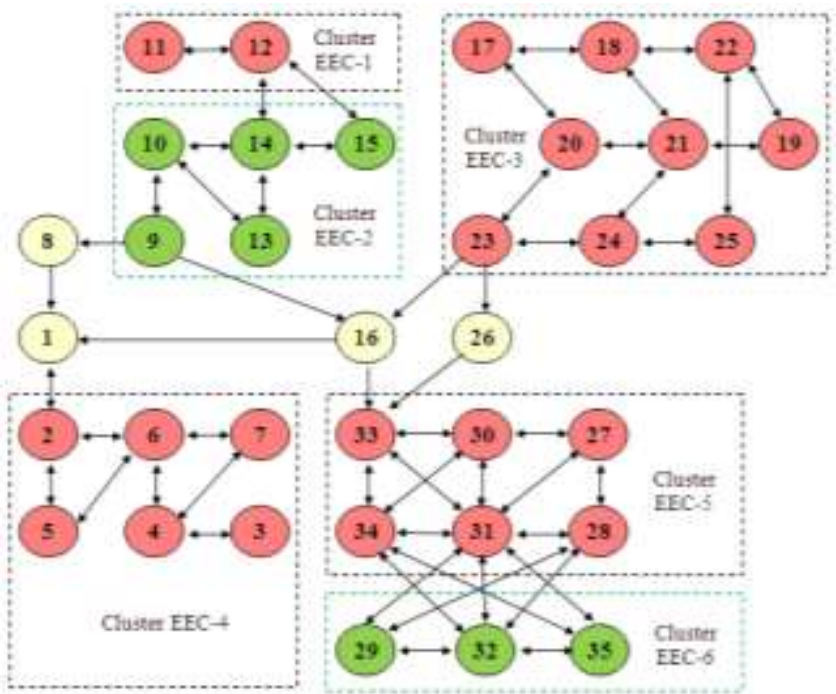

Figure 3. Graph of possible system states in the EEC-model

\section{Interpretation of results}

The analysis of the obtained graphs and the dynamics of the target variables ("Profitability" and "Ecology" for the first model, "Profitability", "Ecology" and "Sociocultural satisfaction" for the second model) allow us to identify the main clusters of states of the simulated systems.
The cluster EE-2 is optimal in the model "Economy \& Ecology". In this cluster, the variable responsible for the ecology of the region decreases, but with a positive second derivative, 
that is, with the passage of time, the deterioration of the ecology slows down, and there is an opportunity to maintain the ecology of the region at a high level. Unfortunately, the development of tourism in any case will cause some damage to the ecology of the region. Nevertheless, there is an opportunity to minimize this damage by pursuing a balanced and coordinated policy in the field of tourism industry development, abandoning the goal of increasing the profitability of the industry by any means.

The EE-4 cluster is not suitable for research purposes, since the system states indicated in this graph reflect the dynamics of the development of variables - at this stage of the development of the tourism industry, it is impossible allow a decrease in profitability due to its already low current values.
At the same time, the optimal at first glance cluster of EE-2 is very unstable. It is easy to get into a dangerous EE-3 cluster from it. The analysis of the information in Table 1 shows that this can happen in the case of high growth rates of the region's infrastructure. However, this cluster allows the possibility of returning to the optimal states of the entire system. The remaining clusters are more dangerous, since they are characterized by the inability to return to their original state. The system can get into these states if the variables go into static states (the first derivative turns to zero), that is, if there is no development of the selected factors.

The optimal EE-2 cluster is characterized by the dynamics of the variables included in the model, shown in Figure 4.
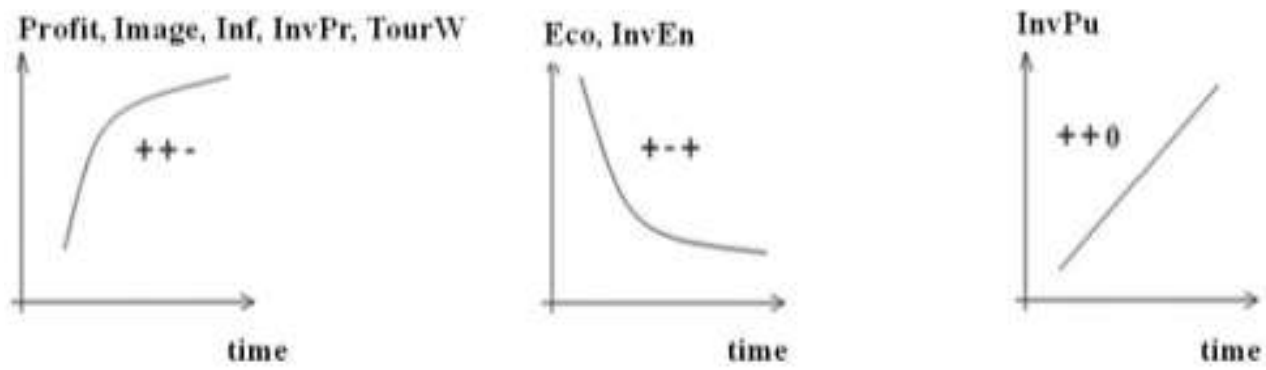

Figure 4. Dynamics of variables in a cluster (model "Economy - Ecology")

The analysis of the mutual dependencies of the variables of the model "Economy \& Ecology" (Table 1) shows that improving the image of the region and the balanced development of infrastructure on its territory will have a beneficial effect on the dynamics of all variables included in the model.

Unlike the first model, there are two good clusters in the model "Economy, Ecology \& Culture" (EEC-2 and EEC-6). In these clusters, as in the first model, the variable responsible for the ecology of the region decreases, but with a positive second derivative. The variables that characterize profitability and sociocultural satisfaction are growing.

It is easy to get from the EEC-2 cluster to the EEC-1 cluster, where the environment will suffer enormous damage. This can happen in the case of high rates of infrastructure growth, as well as with a sharp reduction in public investment in the environment.
It is also easy to get into an undesirable EEC-5 cluster from the EEC-6 cluster, but the possible reasons for the transition will differ. In this cluster, the growth of infrastructure will not have any consequences, since it is characterized by exceptionally high rates of infrastructure growth, and at the same time an acceptable level of ecology is maintained. The only reason for the transition to an undesirable cluster will be a sharp decline in the level of public investment in the environment.

Thus, the EEC- 6 cluster is superior to the EEC-2 cluster for two reasons: firstly, it is more stable, and secondly, it is not irrevocable. Within this cluster, it is possible to move from a moderate growth of the "Sociocultural satisfaction" factor (scenario 29) to an accelerated growth of this factor (scenario 35), while the other factors will remain unchanged. 
The optimal EEC-6 cluster is characterized by the dynamics of the variables included in the model, shown in Figure 5.
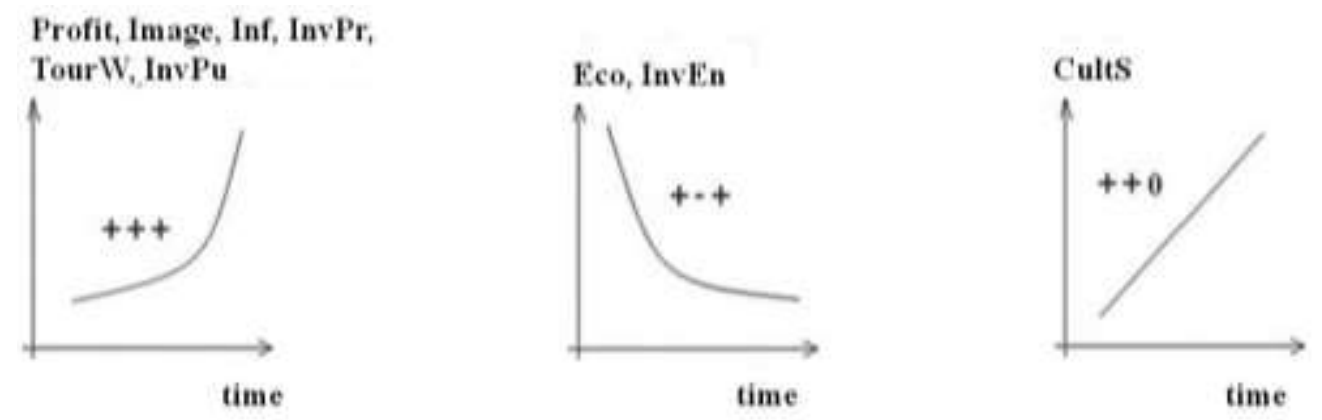

Figure 5. Dynamics of variables in the cluster (model "Economy, Ecology \& Culture")

In the model "Economy, Ecology \& Culture", the optimal cluster ensures the growth of most variables (Profitability, Image, Infrastructure, Private investment, Winter tourism, Public investment) at a higher rate (the second derivative of the triplet is positive) due to the inclusion in the model of a variable that takes into account the sociocultural aspect.

As the analysis of the interdependencies of variables shows, the key factor of both qualitative models is the development of infrastructure. When implementing design solutions to comply with the principles of ecological balance, it is necessary to provide for protective engineering and geological measures during the construction of all objects, compliance with environmental and sanitaryepidemiological norms when placing objects of engineering and transport and recreational infrastructure, comprehensive landscaping and landscaping of the territory, the introduction of a system for separate collection of solid household waste on the territory of the destination, and much more.

\section{Conclusions}

The findings of the study can be summarized as follows. There are several types of sustainability of regional tourism clusters: economic, environmental and sociocultural. To achieve true cluster sustainability, it is necessary to combine and complement all three of these types of sustainability. The main problem of modeling tourist clusters in many destinations is the lack of sufficient statistical data. In addition, the tourism industry is a complex object that cannot always be measured quantitatively, but can be measured qualitatively. Therefore, for the purposes of modeling the stability of regional tourist clusters, taking into account sociocultural factors, the method of qualitative modeling is most suitable. This is a formalized algorithm of logical thinking that allows you to create a simulation model of a complex system.

The first stage of such modeling is to identify all the variables of the qualitative model (both exogenous and endogenous). At the next step, using the methods of formal logic, the method of expert assessments or the results obtained by quantitative methods, it is necessary to determine the paired interdependencies of variables. With the help of graphs of possible dependencies between variables, it is possible to formalize information that cannot be taken into account using ordinary equations. It is obvious that variables are not always connected by an unambiguous dependence, which means that it is not always possible to describe paired relationships between all variables. However, qualitative modeling does not require the definition of all paired dependencies: it is enough to determine a reasonable number of logical relationships. Using a simple algorithm that obeys mathematical principles, it is possible to determine all possible transitions for onedimensional triplets. To illustrate multidimensional qualitative variables, it is convenient to use a directed graph in which the vertices represent a set of scenarios, and the 
directed arrows represent possible transitions between scenarios. The described qualitative model is a flexible modeling tool and allows you to analyze the development of systems that have exceptional properties or are strongly influenced by qualitative factors.

In order to determine all possible qualitative scenarios of models, it is necessary to identify the signs of derivatives of dependent variables based on independent variables and relationships. With the help of the $R$ programming language, a program was written to search for all possible qualitative scenarios. Based on the possible one-dimensional transitions, syntax was written for constructing a graph of possible transitions between the states of the system. Models can be represented in the form of graphs, the vertices of which are the dynamic states of systems. The analysis of the obtained graphs and the dynamics of the target variables allow us to identify the main clusters of states of the simulated systems.

The created algorithm of qualitative modeling of ways of development of sustainable tourism can be used in the future for specific tourism projects, optimization of investments in the tourism industry, as well as for qualitative modeling of complex systems of various spheres of the regional economy.

\section{References}

Aimagambetov, E. B., Bugubaeva, R., Bespayeva, R., \& Tashbaev, N. (2017). Model of sustainable development of tourism industry in Kazakhstan (regional perspective). Viešoji politika ir administravimas. Vol. $16.179-197$. http://doi:10.13165/vpa-17-16-2-02 [2021 07 28]

Aramberri, J. (2010). Modern Mass Tourism. Emerald.

Batista e Silva, F., Marín Herrera, M. A., Rosina, K., Ribeiro Barranco, R., Freire, S., \& Schiavina, M. (2018). Analysing spatiotemporal patterns of tourism in Europe at highresolution with conventional and big data sources. Tourism Management. Vol. 68. 101-115. http://doi.org/10.1016/j.tourman.2018.02.020 [2021 07 28]

Benner, M. (2017). From clusters to smart specialization: tourism in institution-sensitive regional development policies. Economies. Vol. 5. 26. http://doi:10.3390/economies5030026 [2021 07 28]

Buckley, R. (2012). Sustainable tourism: Research and reality. Annals of Tourism Research. Vol. 39. 528-546. http://doi:10.1016/j.annals.2012.02.003 [2021 07 28]

Dujmović, M., \& Vitasović, A. (2015). Postmodern Society and Tourism. Journal of Tourism and Hospitality Management. Vol. 3. No. 9-10, 192-203. http://doi:10.17265/2328-2169/2015.10.003 [2021 07 28]

Fong, S. F., Lo, M. C., \& Songan, P. (2017). Self-efficacy and sustainable rural tourism development: Local communities' perspectives from Kuching, Sarawak. Asia Pacific Journal of Tourism Research. Vol. 22. 147-159. http://doi:10.1080/10941665.2016.1208668 [2021 07 28]

Greenwood, J. B. (2006). Sustainable development in a tourism destination context: a Plimsoll model of sustainability in Tyrell Country, North Carolina (Unpublished doctoral dissertation). North Carolina State University, Raleigh, USA.

He, P., He, Y., \& Xu, F. (2018). Evolutionary analysis of sustainable tourism. Annals of Tourism Research. Vol. 69. 76-89. http://doi:10.1016/j.annals.2018.02.002 [2021 07 28]

Hospers, G.-J., Desrochers, P., \& Sautet, F. (2008). The next Sillicon Valley? On the relationship between geographical clustering and public policy. International Entrepreneurship and Management Journal. Vol. $4 . \quad 1-15$. https://doi.org/10.1007/s11365-008-0080-5 [2021 07 28]

Kazlovski, V., Ganski, U., Platonenka, A., \& Sabalenka, I. (2020). Sustainable development modeling of agritourism clusters. Management Theory and Studies for Rural Business and Infrastructure Development. Vol. 42(2). 118-127. https://doi.org/10.15544/mts.2020.12 [2021 07 28]

Kirshenblatt-Gimblett, B. (1998). Destination Culture: Tourism, Museums and Heritage. University of California Press.

Malmberg, A., \& Power, D. (2006). True clusters: A severe case of a conceptual headache. In: B. Asheim, P. Cooke, \& R. Martin (Eds.). Clusters and Regional Development: Critical Reflections and Explorations. London, Routledge. 50-68

Ottenbacher, M. C., Schwebler, S., Metzler, D., \& Harrington, R. J. (2015). Sustainability Criteria for Tourism Attractions: A Case Study of Germany. International Journal of Social Ecology and Sustainable Development. Vol. 6. 20 -39. https://doi.org/10.3390/su11133691 [2021 07 28]

Paniccia, I. (2006). Cutting through the chaos: Towards a new typology of industrial districts and clusters. In: B. Asheim, P. Cooke, \& R. Martin (Eds.). Clusters and Regional Development: Critical Reflections and Explorations. London, Routledge. 90-114.

Partalidou, M., \& Koutsou, S. (2012). Locally and socially embedded tourism clusters in rural Greece. Tourismos. Vol. 7. 99-116. [2021 07 28]

Porter, M (2000). Location, Competition, and Economic Development: Local Clusters in a Global Economy. Economic Development Quarterly. Vol. 14, No 1. 15-34. https://doi.org/10.1177/089124240001400105 [2021 0728$]$ 


\title{
Sciendo
}

\author{
Management Theory and Studies for Rural Business and Infrastructure Development \\ eISSN 2345-0355. 2021. Vol. 43. No. 4: 457-467 \\ Article DOI: https://doi.org/10.15544/mts.2021.41
}

Porter, M. (1990). The Competitive Advantage of Nations. Macmillan.

Porter, M. (1998a). Clusters and the new economics of competitiveness. Harvard Business Review. Vol. 20. 77-90.

Porter, M. (1998b). On Competition. Harvard Business School Press.

Roelandt, T. J. A., \& den Hertog, P. (1999). Cluster analysis and cluster-based policy making in the OECD countries: An introduction to the theme. Boosting Innovation: The Cluster Approach. Paris, OECD.

Romao, J., Guerreiro, J., \& Rodrigues, P. M. M. (2017). Territory and sustainable tourism development: a space-time analysis on European regions. Region. Vol. 4. 1-17. http://doi:10.18335/region.v4i3.142 [2021 07 28]

Rosenfeld, S. A. (1997). Bringing business clusters into the mainstream of economic development. European Planning Studies. Vol. 5. 3-23. https://doi: 10.1080/09654319708720381 [2021 07 28]

Segarra-Oña, M., Miret-Pastor, L., Peiró-Signes, A., \& Verma, R. (2012). The Effects of Localization on Economic Performance: Analysis of Spanish Tourism Clusters. European Planning Studies. Vol. 20. $1-16$. http://doi:10.1080/09654313.2012.680586 [2021 07 28]

Sharpley, R. (2009). Tourism Development and the Environment: Beyond Sustainability? London, Earthscan.

Spencer, G. M., Vinodrai, T., \& Gertler, M. S. (2010). Do clusters make a difference? Defining and assessing their economic performance. Regional Studies. Vol. 44. 697-715. http://doi:10.1080/00343400903107736 [2021 07 28]

Steenbruggen, J. (2016). Tourism Geography: Emerging Trends and Initiatives to Support Tourism in Morocco. Journal of Tourism \& Hospitality. Vol. 5. 3. http://doi:10.4172/2167-0269.1000224 [2021 07 28]

Swords, J, (2013). Michael Porter's cluster theory as a local and regional development tool: The rise and fall of cluster policy in the UK. Local Economy: The Journal of the Local Economy Policy Unit. Vol. 28.4. https://doi.org/10.1177/0269094213475855 [2021 07 28]

Tymošenko, M., \& Golovach, K. (2018). Modeling of the prospects for sustainable development of agricultural territories by the bayesian networks. Management Theory and Studies for Rural Business and Infrastructure Development. Vol. 40. 263-273. http://doi:10.15544/mts.2018.2 [2021 07 28]

Tyrell, T. J., \& Johnston, R. J. (2005). A dynamic model of sustainable tourism. Journal of Travel Research. Vol. 44. 124-134. http://doi:10.1177/0047287505278987 [2021 07 28] 